\title{
Experimental Study on Aerodynamic Performance of FFA-W3-270 Airfoil for Axial Wind Turbine Blade
}

\author{
Seyed-Reza Jafari-Gahraz ${ }^{1}$, Tholudin Bin Hj. Mat Lazim ${ }^{1}$, Gerry E. Schneider ${ }^{2}$, Masoud Darbandi ${ }^{3}$ \\ ${ }^{1}$ Department of Mechanical Engineering \\ Universiti Teknologi Malaysia, Johour Bahro, Malaysia \\ jseyedreza2@live.utm.my and tholudin@utm.my \\ ${ }^{2}$ Department of Mechanical and Mechatronics Engineering, \\ University of Waterloo, Waterloo, Ontario, N2L 3G1, Canada \\ gerry.schneider@uwaterloo.ca \\ ${ }^{3}$ Department of Aerospace Engineering, Centre of Excellence in Aerospace Systems, \\ Sharif University of Technology, Tehran, P.O. Box 11365-8639, Iran \\ darbandi@sharif.edu
}

\begin{abstract}
The experimental tests are particularly important to achieve the high accuracy results for fluid flow around bodies and exact prediction of aerodynamics characteristics in industrial applications. Additionally the experimental results could be a credit yardstick to the validation of numerical results. In this study, we focus on the experimental investigation to analyse the aerodynamic characteristic of FFA-W3-270 airfoil. The airfoil shape has been adopted according to report for FFA airfoils series. The experiments were conducted at the Universiti Teknologi Malaysia Low Speed Wind Tunnel (UTM-LST). The experiments are accomplished to obtain lift, drag and moment coefficients and pressure distribution under various angles of attacks and the chord flow Reynolds number of $5 \times 10^{5}$ and $1 \times 10^{6}$.
\end{abstract}

Keywords: Experimental, FFA-W3-270, Wind Turbine, Blade, Airfoil, Aerodynamics Coefficients

\begin{tabular}{|c|c|c|}
\hline \multicolumn{3}{|c|}{ Nomenclature: } \\
\hline$A_{e}$ & $=$ & effect area \\
\hline$C$ & $=$ & airfoil chord \\
\hline$C_{D}$ & $=$ & drag coefficient \\
\hline$C_{L}$ & $=$ & lift coefficient \\
\hline$C_{M}$ & $=$ & moment coefficient \\
\hline$F_{L}$ & $=$ & lift force \\
\hline$F_{D}$ & $=$ & drag force \\
\hline$F_{Z}$ & $=$ & side force \\
\hline$F x$ & $=$ & transversal force \\
\hline$P$ & $=$ & static pressure measured \\
\hline$P_{0}$ & $=$ & free steam static pressure \\
\hline $\operatorname{Re}$ & $=$ & Reynolds number $=\rho \mathrm{UC} / \mu$ \\
\hline$U$ & $=$ & free stream velocity \\
\hline$X$ & $=$ & airfoil abscissa \\
\hline$\alpha$ & $=$ & angle of attack \\
\hline$\rho$ & $=$ & density \\
\hline
\end{tabular}

\section{Introduction}

With respects to the widespread development of horizontal axis wind turbine (HAWT) technology to supply higher percentage of electrical energy, choosing of wind's turbine blade airfoils play a vital role in the enhancement of performance and achievement of maximum power output. Basically, the appropriate airfoils for wind's turbine blades are 
those capable to produce high lift to affect the wind turbine to achieve its nominal power are selected. Lissaman [1], Guglielmo and Selig [2], and Olejniczak and Lyrintzis [3] have dedicated great effort to design airfoils to produce high lift at low Reynolds numbers. Lyon et al.[4], Selig et al. [5], Selig [6], Selig and Guglielmo [7] performed wind tunnel tests and it was found that the lift coefficient increase with increasing of angle of attack very slowly much less than $2 \pi$ from inviscid theory. Additionally drag coefficient increase very fast at small angle of attacks and drop significantly after reaching a critical angle of attack. Although experimental test deal with high cost, it could give accurate prediction of aerodynamic characteristics around bodies in a flow fields. In this experimental study, a 27-percent thick FFA-W3-270 airfoil which was designed for pitch-regulated winds turbine, typically located in the root part of wind's turbine blade is selected. In this paper we focus on measuring the pressure, force, and moment around the FFA-W3-270 airfoil then describe their variation versus different angle of attacks and Reynolds numbers.

\section{Experimental Method}

Figure 1 shows the airfoil shape which has been adopted according to report of Björck for FFA airfoils series [8, 9]. The FFA series were designed to be structurally efficient.

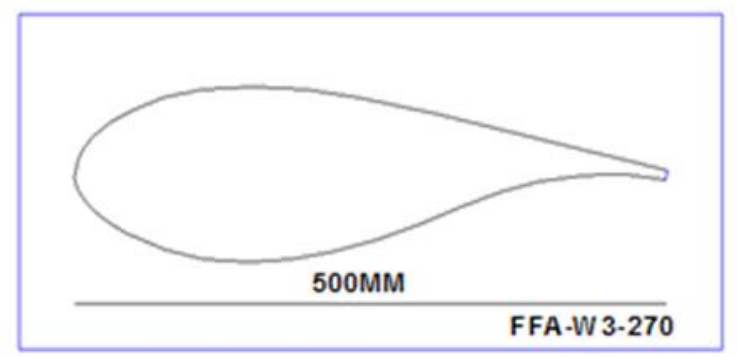

Fig. 1: The FFAW3-270 airfoil profile.

This experimental study was conducted at UTM-LST which is a close circuit, return-type subsonic wind tunnel. The test section is rectangular with a cross section dimensions of $2.0 \mathrm{~m} \times 1.5 \mathrm{~m}$ and $5.8 \mathrm{~m}$ long and the maximum wind speed is $80 \mathrm{~m} / \mathrm{s}$ propelled by a 430kw AC motor. The turbulence level and flow uniformity were about $0.06 \%$ and $0.15 \%$ respectively. The experiments were carried out using a fiberglass FFAW3-270 airfoil model with 500 mm chord length and $750 \mathrm{~mm}$ span wise length which was mounted vertically in the test section. The loads were measured by a JR3-160, 6 component balance mounted on a pyramidal type underfloor support system. The pressure distribution on the airfoil surface was measured using static pressure tapings and recorded via an electronic pressure. Pressure taps were located in bound width $50 \mathrm{~mm}$ at the mid span of airfoil. The experimental tests were carried out for the chord length Reynolds numbers of $5 \times 10^{5}$ and $1 \times 10^{6}$ in wide range of angle of attack.

\section{Experimental Calculations}

The pressure $\left(C_{P}\right)$, Lift $\left(C_{L}\right)$, Drag $\left(C_{D}\right)$, and Momentum $\left(C_{M}\right)$ coefficients as well as the two main lift and drag aerodynamic forces are calculated by below expressions:

$$
\begin{gathered}
\mathrm{C}_{\mathrm{P}}=\frac{\Delta \mathrm{P}}{\frac{1}{2} \rho \mathrm{U}^{2}} \\
C_{L}=\frac{F_{L}}{\frac{1}{2} \rho A_{e} U^{2}} \\
C_{D}=\frac{F_{D}}{\frac{1}{2} \rho A_{e} U^{2}} \\
C_{M}=\frac{M_{Z}}{\frac{1}{2} \rho A_{e} C U^{2}} \\
F_{L}=F_{x} \sin (\alpha)+F_{z} \sin (\alpha)
\end{gathered}
$$




$$
F_{D}=F_{x} \sin (\alpha)-F_{z} \sin (\alpha)
$$

\section{Results and Discussion}

\subsection{Pressure Coefficient Distribution}

Figure 2 illustrates the pressure coefficient distributions of the FFA-W3-270 airfoil at $\operatorname{Re}_{c}=1 \times 10^{6}$ for a limited range of angles of attacks. To avoid complexity, we have plotted the distributions in two diferent plots and limited to an angle of attack of 20 degrees. On the leading edge the pressure value is greater than the free stream pressure $\left(\mathrm{P}_{\infty}\right)$. So Cp is positive but with gradually expansion of flow over upper side of airfoil, pressure reduces very fast and becomes less than free stream pressure $\left(\mathrm{P}_{\infty}\right)$ whereby $\mathrm{Cp}$ in this region is negative. Additionally, as the angle of attack is increased, the maximum suction peak value at the leading edge on the suction side, significantly changes. While the value on the lower surface, does not change very much.
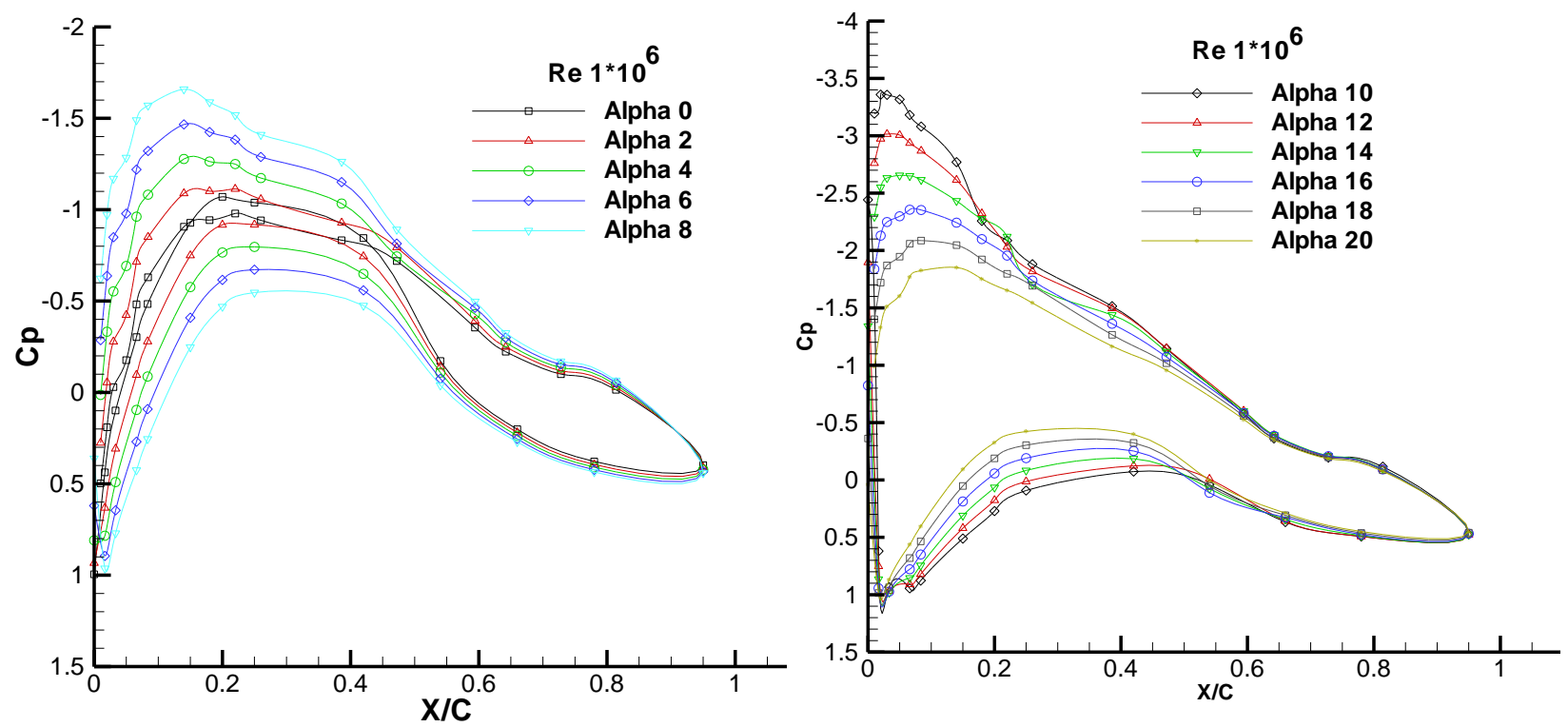

Fig. 2: Pressure coefficient distribution at different.

\subsection{Lift Coefficient Variation}

Figure 3 demonstrates the behaviour of lift coefficient curve at different Reynolds numbers in term of angle of attack for the FFA-W3-270 airfoil. At $\operatorname{Re}_{c}=1 \times 10^{6}$, the measured maximum lift coefficient is 1.52 at 16 degrees. It is mention the lift coefficient at angle of attack of $-2^{\circ}$ is equal to zero (i.e. $\alpha_{\mathrm{cl} 0}=-2^{\circ}$ ). The lift coefficient increased with angle of attack and reached the maximum value (stall angle) then decreased with increasing of angle of attack. It is obvious from the experimental result that increasing of Reynolds number causes an increase in maximum lift coefficient so stall occurs at lower angle of attack.

\subsection{Drag Coefficient Variation}

Figure 4 shows the distribution of drag coefficient in term of the angle of attack for the FFA-W3-270 airfoil at $\operatorname{Re}_{\mathrm{c}}=5 \times 10^{5}$ and $1 \times 10^{6}$. Comparison between two curves indicate that at low angle of attacks, the variation of Reynolds number has no significant effect on drag coefficient value. The contrary, with increasing of angle of attacks and separation of flow, Reynolds number affect could not be ignored. The drag coefficient reduced as the Reynolds number increased. For instance, at stall point, the drag coefficient at $\operatorname{Re}_{c}=5 \times 10^{5}$ is increased over $11.75 \%$ in comparison of $\operatorname{Re}_{c}=1 \times 10^{6}$.

\subsection{Pitching Moment Coefficient Variation}

The pitching moment coefficient about the aerodynamic centre of the airfoil is defined. At this point pitching moment coefficient is almost independent of the angle of attack. This coefficient is zero for symmetry airfoil but for 
cambered airfoil could be have been positive or negative value when it acts in nose-up or nose-down directions respectively. Figure 5 shows the pitching moment coefficient versus the angle of attack. As the moment was calculated about the of aerodynamics centre point $(\mathrm{C} / 4)$, this coefficient does not appreciably change with the angle of attack.

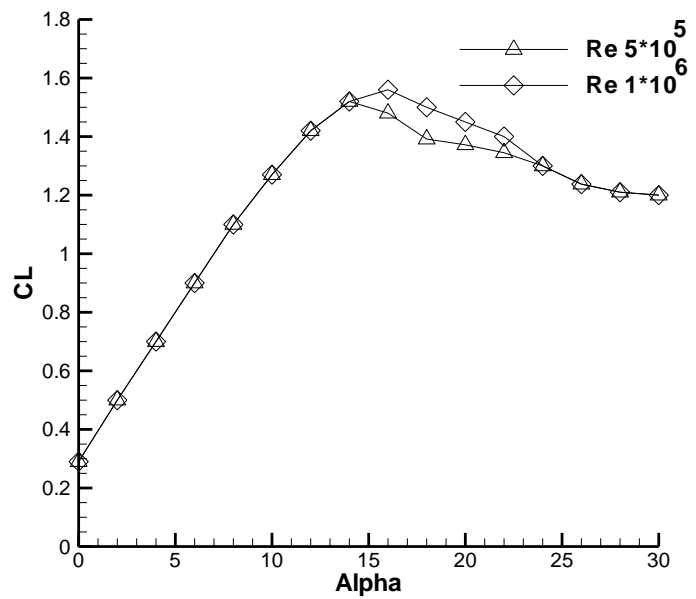

Fig. 3: Lift coefficient at different Reynolds numbers.

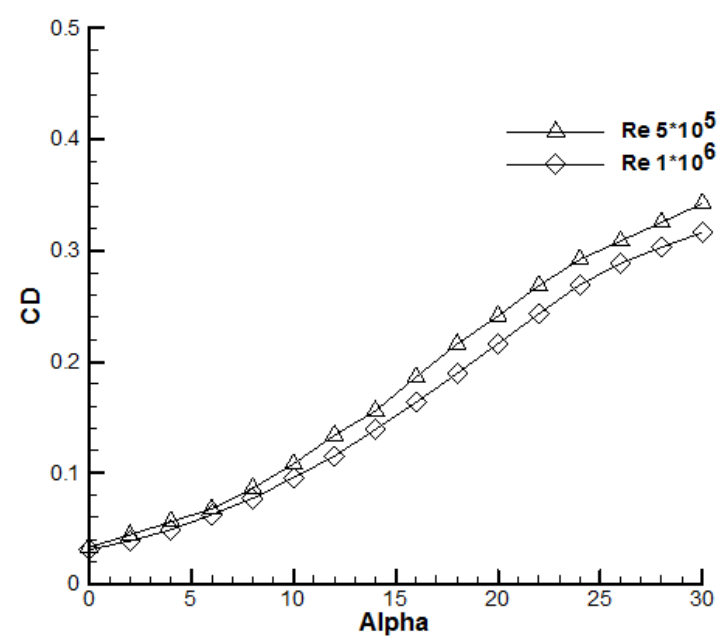

Fig. 4: Drag coefficient at different Reynolds numbers.

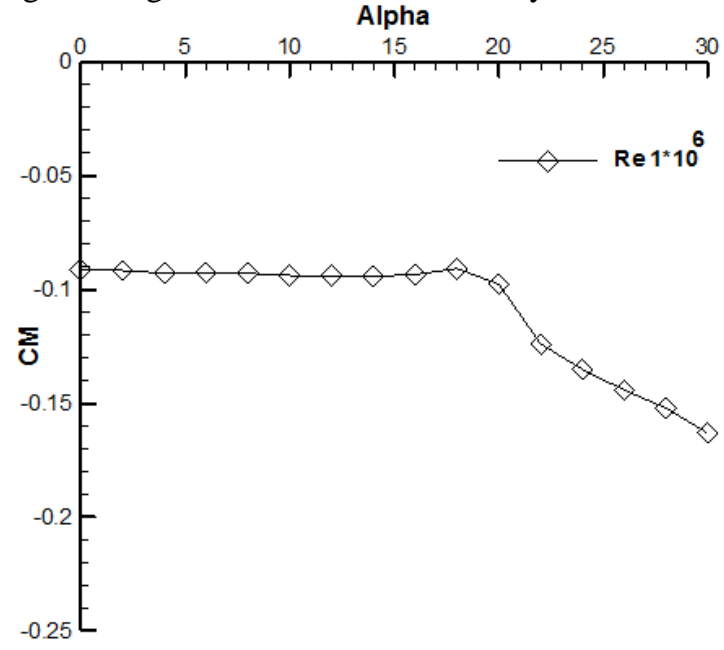

Fig. 5: Pitching moment coefficient. 


\subsection{Polar Diagram}

The lift coefficient versus drag coefficient is one of the most important curve for an airfoil. Carmichael et al. [10] have been investigated the effect of Reynolds number on L/D variation and has shown that the aerodynamic performance at high Reynolds number is often higher than that at low Reynolds number. Figure 6 give some information including $\mathrm{CD}_{\min }$ (Minimum Drag Coefficient), $\mathrm{CL}_{\mathrm{i}}$ (Ideal Lift Coefficient) and $\mathrm{CL}_{\mathrm{d}}$ (Design lift coefficient) for FFA-W3-270 airfoil at two different chord length Reynolds numbers.

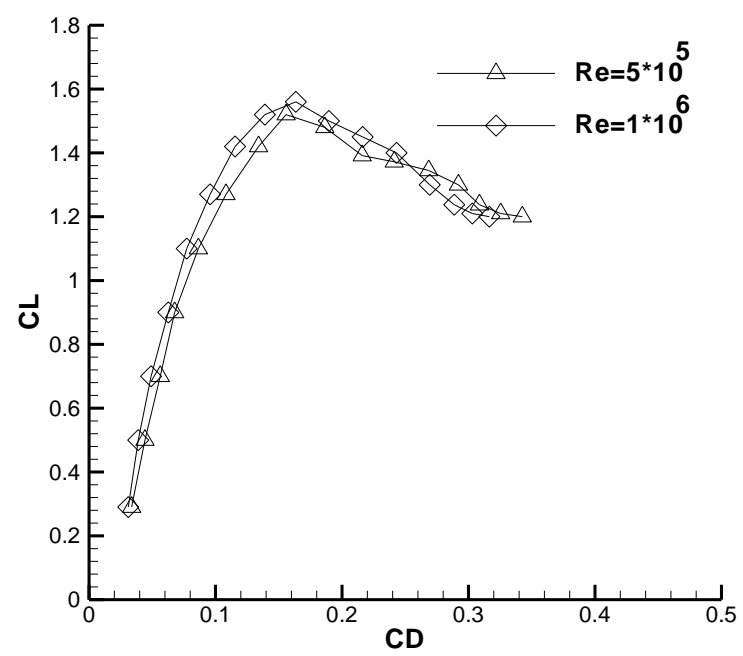

Fig. 6: Polar diagram at different Reynolds numbers.

\section{Conclusion}

This paper presents an experimental measured results of FFA-W3-270 airfoil, under different chord Reynolds numbers and a wide range of angle of attacks. With the increase of the angle of attack, the onset of separation as shown by the forming of separation bubble starts from trailing edge and grows as the angle of attack is further increased. The experimental results show by that increasing of angle of attack, suction peak on upper side of airfoil is maximized. By rising of angle of attack, the lift has a linearly increment up to reach maximum value, after this point (stall), increasing more leads to extremely reduce the lift, consequently by occurring stall incident, a sudden increase appears on the drag coefficient.

\section{Acknowledgements}

The authors would like to thank the Aerolab UTM (Universiti Teknologi of Malaysia) for the use of experimental facilities. Their financial support and help are greatly acknowledged.

\section{References}

[1] P. B. S. Lissaman, "Low-Reynolds-number airfoils," Annual Review of Fluid Mechanics, vol. 15, no. 1, pp. 223-239, 1983.

[2] J. J. Guglielmo and M. S. Selig, "High-lift low Reynolds number airfoil design," Journal of aircraft, vol. 34, no. 1, pp. 72-79, 1997.

[3] J. Olejniczak and A. S. Lyrintzis, "Design of optimized airfoils in subcritical flow," Journal of aircraft, vol. 31, no. 3, pp. 680-687, 1994.

[4] C. A. Lyon, A. P. Broeren, P. Giguere, A. Gopalarathnam, and M. S. Selig, Summary of Low-Speed Airfoil Data, vol. 3. Virginia Beach, VA: SoarTech Publications, 1998.

[5] M. S. Selig, J. F. Donovan, and D. B. Fraser, Airfoils at low speeds. 1989.

[6] M. S. Selig, Summary of low speed airfoil data, vol. 1. SoarTech, 1995.

[7] M. S. Selig and J. J. Guglielmo, "High-lift low Reynolds number airfoil design," Journal of aircraft, vol. 34, no. 1, pp. 72-79, 1997. 
[8] A. Björck, "AERFORCE: Coordinates and calculations for FFA-W1-XXX,FFA-W2-XXX and FFA-W3-XXX series of airfoils for Horizontal Axis Wind Turbine," FFA TN, 1990-15, 1990.

[9] A. Björck, "A Guide to Data Files from Wind Tunnel Test of a FFAW3-211 Airfoil at FFA," Technical Report FFA PV-019, FFA, Bromma, Sweden, 1996.

[10] B. H. Carmichael, Low Reynolds number airfoil survey. National Aeronautics and Space Administration, Langley Research Center, 1981. 